\title{
Managerial Ability and Capital Flows
}

\author{
André C. Silva* \\ Faculdade de Economia, Universidade Nova de Lisboa
}

May 2009

\begin{abstract}
Capital flows with low intensity and flows to middle-income countries. Physical and human capital alone cannot explain this pattern. I present a model to show how managerial ability - the ability to run risky projects - can increase total factor productivity and explain the pattern of capital flows. The model implies that countries with more high-ability managers use more risky projects and have higher productivity. I define proxies for managerial ability with data on physical and human capital, schooling, and entrepreneurship. Consistent with the pattern of capital flows, the model predicts similar returns to capital across countries and higher returns in middle-income countries.
\end{abstract}

JEL classification: F2, F4, L26, O1.

Keywords: capital flows, managerial ability, human capital, entrepreneurs.

${ }^{*}$ Faculdade de Economia, Universidade Nova de Lisboa, Campus de Campolide, Travessa Estevao Pinto, Lisbon, Portugal, 1099-032. Tel: +351-21-380-1600. Fax: +351-21-387-0933. Email: acsilva@fe.unl.pt. I am grateful to Javier Birchenall, Daniel Ferreira, Iliyan Georgiev, Fernanda Llussá, Robert Lucas, José Mata, Ana Reis, participants at various seminars, and two anonymous referees for valuable comments and discussion. Financial support from INOVA and FCT PTDC/ECO/72021/2006 is gratefully acknowledged. Published as Silva, Andre C. (2010). "Managerial Ability and Capital Flows." Journal of Development Economics, 93(1): 126-136, 2010, https://doi.org/10.1016/j.jdeveco.2009.04.005. 


\section{INTRODUCTION}

This paper shows how managerial ability can increase total factor productivity and explain the pattern of capital flows. Capital flows with low intensity and flows to middle-income countries. We can explain this pattern if returns to capital are similar across countries and higher in middle-income countries. Physical capital and human capital alone cannot explain the variation of output across countries and cannot explain capital flows (Lucas 1990, Caselli 2005, among others). I calibrate the model and calculate returns to capital with different proxies for managerial ability. As needed to explain the pattern of capital flows, I find returns to capital similar across countries and higher in middle-income countries. ${ }^{1}$

I use the model of Imrohoroglu and Kumar (2004). Imrohoroglu and Kumar explain the low intensity of capital flows and the direction of capital flows with intermediation costs. I extend their framework to allow for different distributions of managerial abilities and set the intermediation costs to zero. The motivation for this is that intermediation costs have been decreasing with market deregulation and financial innovation but the pattern of capital flows has not changed. Capital continues to flow with low intensity and to middle-income countries. The difference in conditions to foster managerial abilities, however, is large and it is more difficult to revert. Can a model without intermediation costs generate the same pattern: middle-income countries with higher returns? Surprisingly, only the differences in managerial abilities,

\footnotetext{
${ }^{1}$ The low intensity of capital flows refers to the observed capital flows compared to the predictions of the neoclassical model on the returns to capital. The rich countries (those in the highest quartile of capital per worker in Klenow and Rodriguez-Clare 1997) have 40 times the capital per worker of poor countries (those in the lowest quartile). Given these differences in capital per worker, capital had to flow fast from rich to poor countries. According to the United Nations Conference on Trade and Development, however, outflows minus inflows of foreign direct investment in 2004 from developed countries (Australia, Israel, Japan, Malta, New Zealand, North America, and Western Europe by the United Nations classification) were 250 billion dollars, or only 1 percent of the sum of GDP of these countries. To see that capital flows to middle-income countries, the 50 least developed countries received in 2004 only 3 percent of all inflows to developing countries (UNCTAD 2006).
} 
without the intermediation costs, are able to account for the pattern of capital flows.

One advantage of the model of Imrohoroglu and Kumar is to allow countries to use the technology in different ways. Agents can produce output with a risky and a safe technology. When we include the effects of managerial ability, countries with more high-ability managers use the risky technology more intensively. The composition of risky and safe projects changes according to the distribution of abilities. The technologies of risky and safe projects are available for all countries, but countries with more high-ability managers use the technologies more effectively by using more risky projects. In accordance with this prediction, if we interpret the safe technology as traditional technologies and agriculture, Caselli and Feyrer (2007) show that poor countries use capital more heavily in natural-resource sectors and agriculture. The model clarifies how countries with more high-ability managers use the available technology more effectively.

In the model, managers decide to undertake risky or safe projects. The probability of success in risky projects increases with managerial ability. If all countries have the same distribution of managerial ability then the ranking of returns is the same as in the neoclassical model: returns are higher in countries with less physical capital. Accounting for managerial ability makes returns closer across countries and higher in middle-income countries.

I use data on physical capital and human capital from Klenow and Rodriguez-Clare (1997), on years of education from Barro and Lee (2001), and on entrepreneurship from the Global Entrepreneurship Monitor (Reynolds et al. 2005) to define proxies for managerial ability. When income and managerial ability are positively related, returns in capital-rich countries can be higher than in countries with little capital. Managerial ability overcomes the decrease in the marginal return to capital.

The model implies that total factor productivity (TFP) increases with managerial ability. That is, returns increase, keeping physical and human capital constant, when 
managerial ability increases. Managerial ability works as an unmeasured component of physical or human capital able to affect production. The purpose of the paper is to understand how managerial ability can increase TFP. In particular, to explain how managerial ability increases TFP in a way that (1) returns to capital are similar across countries and (2) returns to capital are slightly higher in middle-income countries to justify the flows of capital from rich and poor countries to middle-income countries. Managerial ability is not, of course, the single explanation for differences in TFP and for the pattern of capital flows. I interpret the probability of having a successful risky project in the model as managerial ability. It can also be interpreted as entrepreneurship, institutions or cognitive abilities that increase the likelihood of having a successful project.

Why are managerial abilities different across countries? If managerial ability is important, we should ask why individuals in poor countries decide not to improve their managerial ability. ${ }^{2}$ What institutions encourage the acquisition of managerial skills $^{3}$ ? The focus of the paper is first to understand how managerial ability increases TFP. The reason in the model is: more high ability managers imply a more heavily use of risky projects. It is the change in the composition of safe and risky projects that implies the reversal in the ranking of capital returns - with higher capital returns in middle-income countries.

In the following three sections, I discuss the model, implications, and conclusions. I discuss the evidence on managerial ability across countries in section 3. All proofs are in the appendix.

\footnotetext{
${ }^{2}$ Prescott (1998), Hall and Jones (1999) and Caselli (2005) also call attention to the question of why there are differences in total factor productivity. Gourinchas and Jeanne (2007) provide evidence that low capital flows can be explained by low productivity in poor countries. Reinhart and Rogoff (2004), on the other hand, consider credit market risk.

${ }^{3}$ Murphy et al. (1991) discuss how institutions affect the allocation of talent to entrepreneurship. Foster and Rosenzweig (1996, 2004) and Bils and Klenow (2000) discuss how expected growth encourages schooling. In a similar way, expected growth and institutions could also encourage the acquisition of managerial skills.
} 


\section{THE MODEL: RISKY PROJECTS AND MANAGERIAL ABILITY}

The main components of the model are intermediaries and managers who decide to undertake safe or risky projects. The model is a version of the framework in Imrohoroglu and Kumar (2004).

There is a continuum of one-period lived, risk neutral managers, with measure one. Their only endowment is human capital. They borrow physical capital from intermediaries to fund their projects. There are two kinds of projects: a safe project and a risky project. The technology of the safe project is $y(k)=A k^{\alpha} h^{1-\alpha}$ where $k$ is physical capital per worker, $h$ is human capital per worker, $\alpha$ is the physical capital share and $A$ is a productivity parameter. The technology of the risky project is $y_{H}(k)=A_{H} k^{\alpha} h^{1-\alpha}$ if the project is successful, and $y_{L}(k)=A_{L} k^{\alpha} h^{1-\alpha}$ if the project fails, $A_{H}>A>A_{L} \geq 0 .^{4}$

Each manager is indexed by the potential to succeed in the risky project, denoted by $a \in[0,1]$. I interpret the potential to succeed in the risky project as managerial ability or entrepreneurship. A manager with ability $a$ has probability $\pi(a)$ of being successful in the risky project. The probability $\pi(a)$ increases with $a$. The outcome of the safe project does not depend on managerial ability. Managerial ability is private information. The distribution of abilities is given by $F$, with density function $f$.

Let $x$ be a proxy for managerial ability. This assumption allows us to associate each country with a distribution of managerial ability. $x$ can be human capital, income, entrepreneurship, or institutions that encourage agents to undertake risky projects or to acquire management skills. In order to obtain analytical results, suppose that the distribution $F$ shifts to the right when $x$ increases. That is, the cumulative distribution of managerial ability $F\left(\cdot \mid x^{\prime}\right)$ first order stochastic dominates $F(\cdot \mid x)$ when

\footnotetext{
${ }^{4}$ It is possible to write the model with risk averse managers. I use risk neutral managers to simplify the model and obtain analytical solutions. With risk neutral managers, we can obtain more intuition for the results, abstract from risk sharing, and focus on managerial ability.
} 
$x^{\prime}>x$. It is easier to find a high-ability manager when $x$ is high.

Intermediaries pool project risk and guarantee a rate of return to capital $r$. Intermediation occurs within each period. Intermediaries cannot make contracts contingent on managerial ability as ability is private information. For this reason, they offer the quantity of capital $k_{r}$ and the interest rate $r_{r}$ for the managers who undertake the risky project, and the interest rate $r_{s}$ for the managers who undertake the safe project. Managers choose the quantity of capital in the safe project given the interest rate $r_{s}$. On the other hand, they have to use $k_{r}$ units of capital, to be determined in equilibrium, if they undertake the risky project and pay the interest rate $r_{r}$. The intermediary appropriates the production if the project fails. ${ }^{5}$

At the beginning of the period, the managers invest in the safe or risky project. At the end of the period, the managers of safe projects and successful risky projects consume their output net of interest payments, the managers of failed projects consume zero, and the intermediaries pay the interest $r$ to consumers.

The sum of capital invested in the safe and risky projects is equal to the total quantity of capital $k$. The division of $k$ into capital in risky and safe projects occurs within the period. We may view the total quantity of capital $k$, available in the beginning of the period, as the result of an intertemporal maximization problem in which consumers decide between consumption and savings. This intertemporal problem is not important to us. The key equilibrium value is the interest rate given the levels of $x, h$ and $k$. The objective is to see how taking into account the ability to run risky projects implies similar equilibrium interest rates across countries given $x, h$ and $k$ for each country. ${ }^{6}$

\footnotetext{
${ }^{5}$ This financial contract is also considered in Imrohoroglu and Kumar (2004). We could also consider verification costs, but this is not essential for the results.

${ }^{6}$ The intertemporal problem is $\max \sum_{t=0}^{\infty} \beta^{t} u\left(c_{t}\right)$ s.t. $c_{t}+k_{t+1}=(1-\delta) k_{t}+r_{t} k_{t}$, where $k_{t}$ is the total quantity of capital in the beginning of each period.
} 


\section{Solving the model}

A manager with ability a decides whether to undertake a safe or a risky project. The manager solves the problem

$$
\max \left\{\max _{k_{s}} y\left(k_{s}\right)-r_{s} k_{s}, \pi(a)\left[y_{H}\left(k_{r}\right)-r_{r} k_{r}\right]\right\} .
$$

The left hand side has the profits if the safe project is undertaken. The right hand side has the expected profits if the risky project is undertaken. The optimal quantity of capital in the safe project is independent of the level of ability. ${ }^{7}$ The intermediary offers the interest rate $r_{s}$ for the safe project and the contract $\left(r_{r}, k_{r}\right)$ for the risky project. As discussed above, it is not possible to offer $k_{r}$ according to the ability of the manager because $a$ is private information. The intermediary offers the same contract for all managers willing to undertake the risky project. The level of capital in risky projects is not exogenous. We determine $k_{r}$ in equilibrium. Private information is not important for the results. I am focusing in the problem with private information because it is more realistic and easier to discuss. Having full information, and so $k_{r}$ as a function of $a$, does not change the conclusions of the paper.

There is a threshold ability level $z$ such that the manager undertakes the safe project if $a<z$, and undertakes the risky project if $a \geq z$. $z$ is such that

$$
\pi(z)\left[y_{H}\left(k_{r}\right)-r_{r} k_{r}\right]=y\left(k_{s}\right)-r_{s} k_{s} .
$$

Given $z$, the measure of successful risky projects, $\Phi(z, x)$, and the measure of unsuc-

\footnotetext{
${ }^{7}$ The payment of human capital is not in the problem because each manager is endowed with human capital. Another way of understanding why the payment of human capital is not in the problem is to consider that managers take the level of human capital in the economy as given. A higher $h$ increases production in safe and risky projects, but managers cannot affect the level of $h$.
} 
cessful risky projects, $\Theta(z, x)$, are defined by

$$
\Phi(z, x) \equiv \int_{z}^{1} \pi(a) d F(a, x) \quad \text { and } \quad \Theta(z, x) \equiv \int_{z}^{1}[1-\pi(a)] d F(a, x)
$$

Assume that intermediaries and managers act competitively and that there is free entry of intermediaries. With these assumptions, the equilibrium values of $z, k_{s}$ and $k_{r}$ coincide with the values that maximize total expected output. Therefore, we obtain $z, k_{s}$ and $k_{r}$ by maximizing total expected output,

$$
\max _{z, k_{s}, k_{r}} F(z, x) y\left(k_{s}\right)+\Phi(z, x) y_{H}\left(k_{r}\right)+\Theta(z, x) y_{L}\left(k_{r}\right)
$$

subject to the resource constraint

$$
F(z, x) k_{s}+[1-F(z, x)] k_{r}=k
$$

Once we find the optimal values of $z, k_{s}$ and $k_{r}$, we obtain the interest rates $r_{s}$ and $r_{r}$ by the marginal condition $r_{s}=y^{\prime}\left(k_{s}\right)$ and by $(2)$.

The first order conditions of this problem imply

$$
\begin{gathered}
\zeta(z, x) y_{H}^{\prime}\left(k_{r}\right)+[1-\zeta(z, x)] y_{L}^{\prime}\left(k_{r}\right)=y^{\prime}\left(k_{s}\right), \\
y\left(k_{s}\right)-\lambda k_{s} \geq \pi(z) y_{H}\left(k_{r}\right)+[1-\pi(z)] y_{L}\left(k_{r}\right)-\lambda k_{r},
\end{gathered}
$$

where $\zeta(z, x)$ is the ratio between the number of successful projects to the total of risky projects, $\zeta(z, x) \equiv \Phi(z, x) /[1-F(z, x)]$, and $\lambda$ is the Lagrange multiplier on the resource constraint (5). The second equation solves with equality if $0<z<1$. $^{8}$ $\zeta(z, x)$ is increasing in $z$, as $\pi$ is increasing in $a$. We will see below that $\zeta$ is also increasing in the proxy for managerial ability $x$.

\footnotetext{
${ }^{8}$ If $z=0$ then equation (7) changes to $y\left(k_{s}\right)-\lambda k_{s}<\pi(0) y_{H}\left(k_{r}\right)+[1-\pi(0)] y_{L}\left(k_{r}\right)-\lambda k_{r}$.
} 
Condition (6) equates the marginal product of risky and safe projects, the first weighted by the fraction of successful and unsuccessful risky projects. Substituting the functional forms of the production functions, it yields the ratio of capital used in risky projects to safe projects,

$$
\frac{k_{r}}{k_{s}}=\left[\zeta(z, x) \frac{A_{H}}{A}+[1-\zeta(z, x)] \frac{A_{L}}{A}\right]^{\frac{1}{1-\alpha}} .
$$

This ratio is important for our purposes because the rate of return to capital increases if more managers engage in risky projects. This ratio is not constant in $x$ because $x$ changes the distribution of managers and, therefore, changes $z$. The effect of $x$ disappears in the neoclassical model. This ratio is constant for a proportional increase in $A_{H}, A$ and $A_{L}$, by the homogeneity of the production function. $k_{r} / k_{s}$ is also constant in $k$ or $h$. That is, if capital increases, with no increase in $x$, then the quantities of capital in risky and safe projects increase in the same proportion. Rich and poor countries have the same composition of risky and safe projects if there is no increase in $x$.

If the fraction of successful risky projects $\zeta$ increases with $x$, then the ratio of capital in risky projects to safe projects increases with $x$. The following proposition guarantees this.

Proposition 1. The fraction of successful risky projects $\zeta(z, x)$ increases with the proxy for managerial ability $x$. As a corollary, $k_{r} / k_{s}$ is increasing in $x$.

The proof of $\zeta_{x}>0$ is involved because both the number of successful risky projects $\Phi$ and the number of risky projects increases when $x$ increases - the numerator and denominator that define $\zeta$. We need the probability $\pi$ increasing in $a$ and $F\left(a, x^{\prime}\right)$ to first order stochastic dominate $F(a, x)$ when $x^{\prime}>x$. A more technical condition is that the density $f$ is positive in the set of abilities, to avoid the possibility of $\zeta$ being constant in $x$. 
We obtain the threshold level of ability $z$ with $(7),(8)$, and $\lambda=y^{\prime}\left(k_{s}\right)$,

$$
\frac{1}{1-\alpha}\left(\frac{k_{r}}{k_{s}}\right)^{\alpha}\left[[\pi(z)-\alpha \zeta(z, x)] \frac{A_{H}}{A}+[(1-\pi(z))-\alpha(1-\zeta(z, x))] \frac{A_{L}}{A}\right] \leq 1
$$

where $k_{r} / k_{s}$ is given by (8), with equality if $0<z<1$.

Recall that the ratio $k_{r} / k_{s}$ does not depend on $k$ or $h$ and so the expression that defines $z$ does not depend directly on physical capital or human capital. Therefore, $z$ does not depend on $k$ or $h$. $z$ depends on the technology parameters and on the proxy for managerial ability $x$. As $k_{r} / k_{s}, z$ is constant for a proportional increase in $A_{H}, A$ and $A_{L}$.

The left-hand side of (9) is the ratio of expected profits from the risky project with ability $z$ to the profits from the safe project. $z=1$ means that all agents undertake the safe project. As $A_{H}>A$, this cannot happen if the probability $\pi(1)$ is close enough to one. Analogously, $z=0$ means that all agents undertake the risky project. This can only happen if $A_{L}$ or $\pi(0)$ are too high, that is, there are sufficient gains even if the project fails. This intuition is confirmed in the proposition below. We can, therefore, easily have conditions to imply existence of $z, 0<z<1$.

Proposition 2. Existence of $z, 0<z<1$. Suppose that $\pi(1)$ is sufficiently close to one and that $A_{L} / A_{H}$ and $\pi(0)$ are sufficiently close to zero. Then, there exists a threshold level of ability $z, 0<z<1$ such that equation (9) is satisfied with equality.

The ability of the managers in the threshold risky project, $z$, increases with the proxy for managerial ability, $z_{x}>0$. Countries with more high-ability managers use a manager with higher ability in the marginal project than countries with less high-ability managers. ${ }^{9}$ Rauch (1991) obtains a similar result in a different model. One of the objectives in Rauch (1991) is to show that countries with more skilled

\footnotetext{
${ }^{9}$ In Imrohoroglu and Kumar (2004), in contrast, intermediation costs restrict the use of capital in risky projects and imply higher managerial ability in the marginal project in countries with less capital. I analyze further the different predictions in the next section.
} 
workers (richer countries) export managers and import skilled employees. The same conclusions would apply to the present paper.

To show that $z$ increases in $x$, define $\Lambda$ as the left-hand side of (9). With $0<z<1$, $z$ is given by $\Lambda(z, x)=1$. Therefore, $z_{x}=-\Lambda_{x} / \Lambda_{z}$. We have $\Lambda_{x}<0$ in general and $\Lambda_{z}>0$ for certain conditions given below, usually valid. Intuitively, $\Lambda$ decreases with $x$ because the ratio $\zeta$ of successful risky projects to the total of risky projects increases when $x$ increases, and so capital in risky projects increases. Therefore, returns decrease in the marginal risky project relative to returns in the marginal safe project. As a result, $\Lambda$ decreases. $\Lambda_{z}>0$ means that returns increase in the marginal risky project relative to the returns in the marginal safe project when managerial ability increases. With $\Lambda_{x}<0$ and $\Lambda_{z}>0, z_{x}>0$.

Proposition 3. $z$ is increasing in $x$. Suppose that $\zeta_{z}<1 / \alpha$ or, alternatively, that the distribution of abilities is not concentrated in any level of ability $(f(a, x)$ is small). Then, the threshold ability level $z$ increases with the proxy for managerial ability, $x$.

Define $\Gamma(x)$ as the ratio of the total quantity of capital to the capital used in safe projects, $\Gamma(x)=k / k_{s}$. By the resource constraint (5),

$$
\Gamma(x)=F(z(x), x)+[1-F(z(x), x)] k_{r} / k_{s} .
$$

$\Gamma$ is known once we have the equilibrium value of $z$ in (9). We obtain the value of $k_{s}$ by $k_{s}=k / \Gamma(x)$ and the value of $k_{r}$ by (8). We obtain $r_{s}$ and $r_{r}$ by $r_{s}=\alpha A k^{\alpha-1} h^{1-\alpha}$ and $r_{r}$ by (2). This completes the determination of the endogenous variables in the model. We will see that $\Gamma(x)$ summarizes how managerial ability affects total factor productivity and how managerial abilities increases returns to capital. 


\section{IMPLICATIONS: RETURNS TO CAPITAL}

Returns to capital depend on the quantity of physical and human capital and on the distribution of managerial abilities. A favorable distribution of managerial abilities increases returns to capital. Economies with little capital may have low returns to capital if it is difficult to find high-ability managers to run projects.

Revenues of intermediaries from safe and risky projects are given by

$$
r e v=F(z, x) r_{s} k_{s}+\Phi(z, x) r_{r} k_{r}+\Theta(z, x) A_{L} k_{r}^{\alpha} h^{1-\alpha} .
$$

The first term in the right hand side are revenues from safe projects. The remaining terms account for revenues from risky projects. The intermediary collects the output of unsuccessful projects. We have $r_{r}$ given by equation (2) and $r_{s}=\alpha A k_{s}^{\alpha-1} h^{1-\alpha}$. Substituting the values of the interest rates and using the expression of $\Gamma$ in (10), we have

$$
r e v=A \Gamma(x) k_{s}^{\alpha} h^{1-\alpha}-A k_{s}^{\alpha} h^{1-\alpha}(1-\alpha)\left(F(z)+(1-F(z)) \frac{\zeta(z, x)}{\pi(z)}\right) .
$$

Returns to capital are defined as $r=r e v / k$. Setting this value of $r$ implies zero profits for the intermediaries. To analyze the rate of return to capital, focus on the first term in the expression of returns and substitute $k_{s}=k / \Gamma .{ }^{10}$ We have

$$
r \approx A \Gamma(x)^{1-\alpha} k^{-(1-\alpha)} h^{1-\alpha} .
$$

$\Gamma(x)$ summarizes the effect of the distribution of managerial abilities. As the proxy for managerial ability increases, the value of $\Gamma$ increases.

\footnotetext{
${ }^{10}$ The second term is the effect of private information. I use the approximation to explain the mechanism of the model. The calibration and predictions that follow were obtained with the complete expression in (12).
} 
$A \Gamma(x)^{1-\alpha}$ is total factor productivity. To see this, consider the expression for total output, $y=F(z, x) y_{s}\left(k_{s}\right)+\Phi(z, x) y_{H}\left(k_{r}\right)+\Theta(z, x) y_{L}\left(k_{r}\right)$. This expression yields

$$
y=A \Gamma(x)^{1-\alpha} k^{\alpha} h^{1-\alpha}
$$

Therefore, we can express differences in managerial ability as differences in TFP in one closed form. TFP can be written as a function of managerial ability. The contribution of the model is to provide a way to understand how managerial ability increases TFP. TFP is higher because the number of risky projects increases with the number of high ability managers.

Proposition 4. TFP increases with $x$. Suppose that $z_{x}$ is small or, alternatively, that the distribution of abilities is not concentrated in any level of ability $(f(a, x)$ is small). Then, $\Gamma(x)$ is increasing with $x$ and hence TFP increases with $x$.

$k$ and $h$ do not affect $\Gamma$. If physical or human capital, however, have positive correlation with factors that change the potential of managers to be successful in risky projects, then the difference in returns to capital across countries changes. Richer countries can have higher returns to capital. This is more likely to happen in middleincome countries, which have a higher level of capital than poor countries but have a much different distribution of managers. If managerial ability is imperfectly captured by aggregate measures of physical and human capital, such as $k$ and $h$, then the variation of $k$ and $h$ alone cannot explain the variation in TFP. ${ }^{11}$

As $\Gamma(x)=k / k_{s}(x)$, when $\Gamma$ increases then the quantity of capital invested in the safe project $k_{s}$ decreases. The rate of return to capital depends on the number of risky projects. By the formula of returns, $r \approx A k_{s}^{-(1-\alpha)} h^{1-\alpha}$. If capital in safe projects

\footnotetext{
${ }^{11}$ Bils and Klenow (2000), Caselli (2005) and others find that physical and human capital alone cannot explain the variation in TFP. There is also a discussion whether the direction of causality is from human capital development (schooling) to growth or from growth to human capital. Bils and Klenow (2000), Kumar (2003) and Foster and Rosenzweig $(1996,2004)$ discuss the direction of causality and analyze further the relation among schooling, human capital and growth.
} 
increases, then returns to capital decrease. More high ability managers imply more risky projects. Two economies with the same level of human capital and physical capital can have different returns if they have different distributions of managerial abilities. We know that the endowments of human capital and physical capital are related to TFP. What we have here is an explanation for why human capital (in the form of managerial ability) is positively correlated with TFP.

\section{Numerical Analysis}

Capital flows with little intensity. Capital flows from rich and poor countries to middle-income countries. I explain this pattern by showing that returns to capital can be close across countries and higher in middle-income countries. This happens in the model because managerial ability increases TFP by the increase in risky projects.

To calculate the quantitative predictions of the model, I use data on physical capital and human capital in Klenow and Rodriguez-Clare (1997, 2005), on educational attainment in Barro and Lee (2001), and on entrepreneurship from the Global Entrepreneurship Monitor (GEM) (Reynolds et al. 2005). I first relate the distribution of managerial abilities with physical capital, human capital and higher education. I later relate the distribution of managerial abilities with indicators of entrepreneurship. More human capital and physical capital increase the number of managers able to be successful in a risky project. Human capital and physical capital-past investments in education or equipment - make management more effective, for example, by improving management techniques and communication equipment. Moreover, Bates (1990) finds a positive relation between years of higher education and entrepreneurship. ${ }^{12}$ In the end of this section, I discuss further the relation between managerial ability and education.

\footnotetext{
${ }^{12}$ Klenow and Rodriguez-Clare construct the measures of human capital from Barro and Lee. I use directly the data of educational attainment in the specifications with higher education. See Lazear (2005) for a theory of entrepreneurship. A different approach is to use the distribution of firm size to infer the distribution of managerial talent (Lucas 1978). Data on firm size across countries, however, is usually not comparable or not available, especially for low-income countries.
} 
Suppose that the distribution of managerial abilities is $F(a, x)=a^{x}$, where $x$ is positively related to physical or human capital. Denote the level of physical and human capital in country $i$ by $k_{i}$ and $h_{i}$, and the average number of years in higher

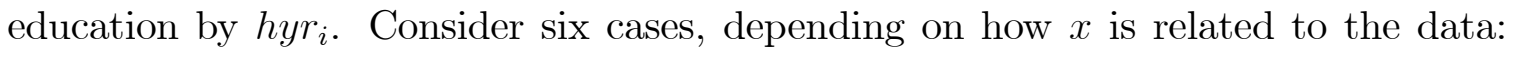
$x=$ hyr $_{i} /$ hyr $_{1}, x=h_{i} / h_{1}, x=k_{i} / k_{1}, x=\left(h_{i} r_{i} / h y r_{1}\right)^{1-\alpha}, x=\left(h_{i} / h_{1}\right)^{1-\alpha}$ and $x=\left(k_{i} / k_{1}\right)^{\alpha}$, where $i=1$ denotes the smallest values of $h y r, h$, or $k$. The first three cases directly relate the proxy with higher education, human capital, and physical capital. The other cases take into account the shares of human capital and physical capital (I later relate $x$ with indicators of entrepreneurship across countries, and discuss how $x$ can be related to institutions).

The distribution of abilities in the country with lowest physical or human capital is uniform- $F(a, x)=a$ when $i=1$ - and the distribution of abilities with higher proxies first order stochastically dominates the distribution of abilities with lower proxies. This specification highlights the main mechanism of the model to affect returns to capital. It is easier to find a high-ability manager as human capital or physical capital increase.

For simplicity, the probability of success in the risky project is linear, $\pi(a)=a$. Given the functional forms of $F(a, x)$ and $\pi(a)$, we have $\zeta(z, x)=\frac{x}{1+x} \frac{1-z^{1+x}}{1-z^{x}}$. The assumption $\pi(a)=a$ is intended to keep $\pi$ the simplest as possible. It is possible to replicate changes in $\pi$ with changes in $F$. For example, an economy with higher probability of success for each ability level (higher $\pi(a)$ ) may behave as an economy with smaller probabilities of success but more high-ability managers.

The model transfers the explanation of capital flows from intermediation costs to managerial ability. To make this clear, I first apply the same data of Imrohoroglu and Kumar (2004) to the model, now with zero intermediation costs but with differences in managerial ability. Imrohoroglu and Kumar use data from Klenow and RodriguezClare (1997), which calculate physical and human capital for 1985. I later update 
physical and human capital with Klenow and Rodriguez-Clare (2005), which calculate physical and human capital for 2000 (it does not change results), and I add evidence on entrepreneurship to proxy for managerial ability.

The dataset of Klenow and Rodriguez-Clare (1997) has 98 countries in different regions and with large differences in income and capital. The country with highest physical capital per worker is Switzerland, with 1.79, 180 times the value of the country with lowest capital per worker, the Democratic Republic of the Congo (formerly Zaire), with 0.01. Capital per worker is normalized to the level of the United States, with $k=h=1$. The variation in human capital is also large. The highest human capital per worker is 100 times the lowest human capital per worker (in the United States, with 1, and in Niger, with 0.01).

Following the procedure of Imrohoroglu and Kumar, I grouped the countries in four quartiles from the lowest to the highest physical capital per worker: $i$ refers now to a quartile, and $k_{i}, h_{i}$ and $h y r_{i}$ refer to the averages of physical capital, human capital and years of higher education of each quartile. We have then four points, each representing a group of 22 countries. ${ }^{13}$ What I refer to as poor countries are the countries in the lowest quartile. The middle-income countries are the countries in the second and third quartiles, and the rich countries are the countries in the highest quartile. Two countries in the first quartile are Tanzania and Ghana-18 of the 22 countries in the first quartile are in Africa. Examples of two countries in the other quartiles are Honduras and Indonesia in the second, Brazil and South Korea in the third, and Denmark and the United States in the fourth. The countries are ordered by capital per worker because capital is the relevant variable for returns to capital in the neoclassical model. The order of countries in income per capita is almost the

\footnotetext{
${ }^{13}$ Following the procedure of Imrohoroglu and Kumar, I also removed 10 countries with high TFP levels, probably caused by measurement problems. The countries are Algeria, Congo, Iran, Iraq, Jordan, Mexico, Syria, Trinidad and Tobago, Tunisia, and Venezuela. The values of $k, h$ and hyr of each quartile are $k_{i}=0.024,0.086,0.279,1.033$ (rounded to $0.025,0.1,0.275,1$ ); $h_{i}=0.049,0.150$, 0.394, 1; and $h_{y r}=0.042,0.204,0.387,0.659$.
} 
same, the correlation of the logs of capital and income per worker is 0.96 .

The variety of countries is an advantage of the dataset of Klenow and RodriguezClare. We later use the dataset of Caselli and Feyrer (2007) and, as mentioned above, the GEM dataset (both described later). These two datasets have less countries, and the countries are concentrated in the highest quartiles of Klenow and RodriguezClare. There are no countries of the lowest quartile in Caselli and Feyrer and there is only one country of the lowest quartile (Uganda) in the GEM dataset.

I assume that the capital share $\alpha$ is equal to 0.35 and the depreciation rate is equal to 9 percent in all countries. For the productivity parameters $A_{H}, A$ and $A_{L}$, I set $A_{L}=0$ and calculate $A_{H}$ and $A$ such that the net return is equal to 7 percent and the capital-output ratio is equal to 3 in the richest quartile. ${ }^{14}$ See appendix for the calibrated values of $A_{H}$ and $A$. I keep the corresponding values of $A_{H}$ and $A$ fixed in each specification and vary the values of physical and human capital. Returns are calculated by $r_{i}=\operatorname{rev}_{i} / k_{i}$, where the intermediary's revenue $r e v_{i}$ is given by (12).

Figure 1 shows the results. The figure has seven lines, six for each proxy of $x$ and one for the neoclassical model, with $x=1$. Each line has four points, for each capital quartile in Klenow and Rodriguez-Clare (1997). (The figure with data from Klenow and Rodriguez-Clare (2005) is similar. It is in Fig 2.) According to the model, returns to capital in all countries are between 6 and 10 percent, with higher returns in middleincome countries (third quartile). This pattern appears in all six specifications with managerial ability. The model predicts much closer returns across countries than the neoclassical model. Returns closer across countries imply that capital flows with low intensity. Higher returns in middle-income countries imply that capital flows to

\footnotetext{
${ }^{14}$ Imrohoroglu and Kumar (2004) also follow this calibration. The difference is that they do not vary the distribution of abilities as income increases. They explain the pattern of capital flows by the introduction of intermediation costs $e$ in each country. In comparison to their model, I set $e=0$ and explain changes in returns on capital with changes in managerial abilities. Their model collapses to the neoclassical model when $e=0$. The present model collapses to the neoclassical model when $x$ does not vary across countries.
} 


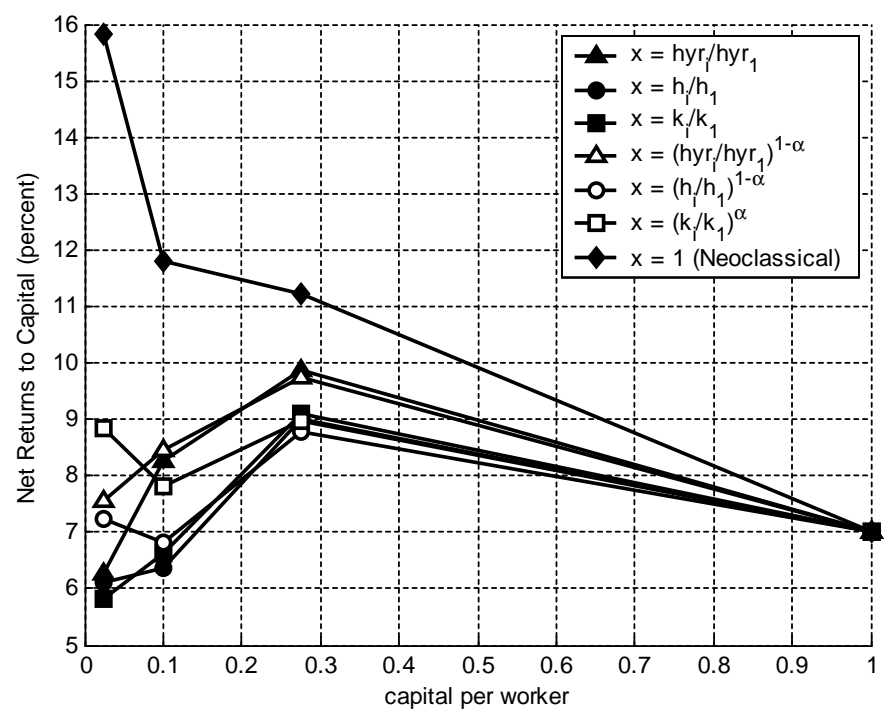

FIG. 1. Net returns to capital $(r-\delta)$ for different assumptions about the proxy $x$. Neoclassical: $y=A k^{\alpha} h^{1-\alpha}$. Capital per worker obtained from grouping the countries in quartiles and normalizing to the level of the richest quartile, data from Klenow and Rodriguez-Clare (1997). Human capital for each quartile: $h_{i}=0.049,0.150,0.394$, and 1 . The model is calibrated to imply returns of 7 percent in the highest quartile.

middle-income countries. More precisely, the model predicts that capital flows with low intensity to countries in the third quartile of capital per worker.

The neoclassical returns in figure 1 , calculated with $x=1$ for all quartiles, take into account human capital in the production function, as in Lucas (1990). Without human capital, returns go much beyond the limits of the figure. Even with human capital, the neoclassical model predicts that net returns in the lowest quartile are more than twice the net returns in the richest quartile.

All deviations from the neoclassical model are the result of changes in the distribution of managerial abilities. According to the specification of $x$, the median of the distribution of abilities increases from 0.5 , in the lowest quartile, to around 0.9 in the highest quartile. ${ }^{15}$ Is this variation excessive? According to the data, the level of

\footnotetext{
${ }^{15}$ The median in the highest quartile varies from 0.83 when $x=\left(k_{i} / k_{1}\right)^{\alpha}$ to 0.98 when $x=k_{i} / k_{1}$.
} 
human capital in the highest quartile is 20 times the level in the lowest quartile, and the corresponding level of physical capital is 40 times the level in the lowest quartile. Educational quality increases even more the difference in human capital (Hanushek and Woessmann 2007). It would not be a surprise to see substantial differences in the distribution of managerial abilities across countries. It is possible that the true distributions of abilities are such that poor countries have even fewer high-ability managers as compared to rich countries than I assume in these exercises. ${ }^{16}$

Table 1 shows gross returns (not discounting depreciation) relative to returns in the highest quartile of capital per worker. In the neoclassical model, returns in the first quartile are 11 times higher than returns in the highest quartile. The difference decreases to 1.55 times when we add human capital to the production function. Returns are much closer when we add the effect of the distribution of managerial abilities. Returns in middle-income countries exceed those in poor and rich countries. Returns are lowest in poor countries under the specifications with $x=$ hyr $_{i} /$ hyr $_{1}$, $x=\left(h y r_{i} / h y r_{1}\right)^{1-\alpha}, x=h_{i} / h_{1}$ and $x=k_{i} / k_{1}$ but not under $x=\left(h_{i} / h_{1}\right)^{1-\alpha}$ and $x=\left(k_{i} / k_{1}\right)^{\alpha}$. This occurs because the proxy varies less in the last two specifications. The highest returns are for countries in the third quartile.

The reason for the increase in returns to capital from the first to the third quartile is the increase in the relative number of risky projects. Risky projects, if successful, are more productive than safe projects. Countries with more high-ability managers benefit more from the risky technology. There are more risky projects in economies with more high-ability managers, although both technologies are available in all countries.

\footnotetext{
${ }^{16}$ The flow of managers from rich to poor countries could increase returns in poor countries. The implicit assumption is that there are factors such as local knowledge (as culture or language), externalities in ability, or fixed costs (as difficulty in matching jobs for family members) that make difficult the migration of managers across countries.
} 
Table 1. Gross Returns Relative to the Highest Quartile and Share of Risky Projects

\begin{tabular}{cccccccc}
\hline & Neoclassical $A k_{i}^{\alpha}$ & \multicolumn{2}{c}{$x=h y r_{i} / h y r_{1}$} & \multicolumn{2}{c}{$x=h_{i} / h_{1}$} & \multicolumn{2}{c}{$x=k_{i} / k_{1}$} \\
$\boldsymbol{k}$ & Return & Return & Share & Return & Share & Return & Share \\
\hline 0.025 & 11.0 & 0.95 & $41.0 \%$ & 0.94 & $39.8 \%$ & 0.93 & $37.7 \%$ \\
0.100 & 4.47 & 1.08 & $89.9 \%$ & 0.96 & $76.3 \%$ & 0.98 & $82.3 \%$ \\
0.275 & 2.31 & 1.18 & $98.3 \%$ & 1.12 & $96.8 \%$ & 1.13 & $98.6 \%$ \\
1.000 & 1.00 & 1.00 & $99.9 \%$ & 1.00 & $100.0 \%$ & 1.00 & $100.0 \%$ \\
\hline \multicolumn{2}{c}{ Neoclassical $A k_{i}^{\alpha} h_{i}^{1-\alpha}$} & $x=\left(h y r_{i} / h y r_{1}\right)^{1-\alpha}$ & $x=\left(h_{i} / h_{1}\right)^{1-\alpha}$ & $x=\left(k_{i} / k_{1}\right)^{\alpha}$ \\
$\boldsymbol{k}$ & Return & Return & Share & Return & Share & Return & Share \\
\hline 0.025 & 1.55 & 1.03 & $48.2 \%$ & 1.02 & $46.7 \%$ & 1.12 & $53.4 \%$ \\
0.100 & 1.30 & 1.09 & $81.4 \%$ & 0.99 & $70.7 \%$ & 1.05 & $69.4 \%$ \\
0.275 & 1.26 & 1.17 & $91.2 \%$ & 1.11 & $88.3 \%$ & 1.12 & $80.2 \%$ \\
1.000 & 1.00 & 1.00 & $96.2 \%$ & 1.00 & $97.3 \%$ & 1.00 & $90.9 \%$ \\
\hline
\end{tabular}

$x$ : proxy for managerial ability. Neoclassical: model with $x=1$ for all quartiles. Share of risky projects in the neoclassical cases: 69.6 percent. The model is calibrated so that gross returns in the highest quartile are 0.16. Source of $k$ : Klenow and Rodriguez-Clare (1997).

As risky and safe technologies are available in all countries, the risky technology should require approximately the same minimum level of managerial ability in all countries. That level of ability, $z$, equates expected profits in risky and safe projects. A biotechnology company in the United States and in India would require approximately the same minimum level of managerial ability. We showed, however, that $z$ increases with $x$. To reconcile the intuition that risky projects should require approximately the same minimum managerial ability, the effect of $x$ on $z$ must be small.

The simulations confirm the intuition. $z$ does not increase much, about 2 percent, from 0.673 to 0.686 , with $x=h y r_{i} / h_{y r}$ (the values are similar for the other proxies) from the poorest to the richest quartile. The manager with lowest ability in the risky project has similar ability in rich and poor countries. This prediction does not mean that the average ability in risky projects is the same in both countries. Rich countries have more high ability managers above the minimum level. The prediction means that innovative companies in poor and rich countries require approximately the same minimum level of managerial ability, slightly more in rich countries. There are less innovative projects in poor countries. When they exist, however, their managers 
can communicate with the managers in rich countries, as they have similar abilities.

The opposite prediction about $z$ happens in Imrohoroglu and Kumar (2004). When risky projects pay intermediation costs, $z$ increases to equate expected profits in risky and safe projects. The effect of intermediation costs is weaker with more capital, and so $z$ decreases when capital increases: rich countries have managers with lower ability in risky projects than poor countries. In the present paper, with frictionless credit, $z$ does not change if $k$ or $h$ increases. $z$ increases if the distribution of managers is more favorable (when $x$ increases). As $x$ is positively correlated with $k$, the model here implies that $z$ increases when capital increases. We should expect countries with more high-ability managers to increase $z$. These countries use more capital in risky projects and should increase $z$ to equate profits in risky and safe projects. ${ }^{17}$

The simulations imply that $z$ increases little: for those in risky projects, managerial ability in rich and poor countries is approximately the same. ${ }^{18}$ Risky, innovative companies should compete internationally. Even though the general distribution of abilities is different, it is plausible to expect managers to have approximately the same ability once the project is undertaken if the technology is the same across countries.

In addition to gross returns, table 1 shows the share of output produced from risky projects relative to total output. Countries with more high-ability managers use their capital to fund more risky projects. This has a positive effect on returns. The model predicts that poor countries tend to adopt safe technologies, usually available in traditional sectors, while rich countries tend to adopt new, risky technologies. In support of this prediction, Vandenbussche et al. (2006) find that countries with more skilled workers are closer to the technological frontier. These countries adopt newer

\footnotetext{
${ }^{17}$ Rauch (1991), in a different model, gives additional intuition for having $z$ higher in richer countries.

${ }^{18} z$ increases little because the effect of $x$ is indirect. $x$ increases the fraction of successful risky projects, $\zeta$, which then increases capital in risky projects and increases $z$. The positive effect of $x$ on $z$ can be made stronger if the probability of sucess in risky projects increases fast when ability increases $\left(\pi^{\prime}(a)\right.$ large).
} 
and riskier technologies.

The returns in figure 1 and table 1 agree with the empirical estimations of Caselli and Feyrer (2007). In an independent study, Caselli and Feyrer find returns to capital of 6.9 percent in poor countries and 8.4 percent in rich countries. I find returns between 6 and 10 percent, shown in figure 1. With the standard deviations calculated by Caselli and Feyrer (1.9 percent for rich countries and 3.7 percent for poor countries), the estimations of returns to capital are between 3.2 and 10.6 percent for poor countries and 6.5 and 10.3 percent for rich countries, consistent with figure 1. (These values also agree with Fig. 2, with the more recent data of Klenow and Rodriguez-Clare 2005.) Considering gross returns, by adding the depreciation of 0.06 in Caselli and Feyrer, gross returns in rich countries are 1.12 times the gross returns in poor countries. Again, a number consistent with the model with managerial ability in table 1.

Rich countries in Caselli and Feyrer are the countries with income per worker from Portugal and higher and poor countries are the countries from Malaysia and lower. To compare predictions and estimations for each quartile in figure 1, I arranged the countries in Caselli and Feyrer in the quartiles used here. South Korea, for example, is in both datasets and it is in the third quartile (from the 53 countries in Caselli and Feyrer, this arrangement implies 20 countries in the richest quartile, 12 in the third, and 10 in the second, no country of the poorest quartile is in the dataset of Caselli and Feyrer $\left.^{19}\right)$. The average of the estimations in Caselli and Feyrer for each quartile are 8.1, 8.3, and 8.3 for the richest, third and second quartiles. Approximately the same for all quartiles, 8 percent. The estimations in Caselli and Feyrer for each quartile would appear as a straight line in figure 1, passing through 8 percent. As the model

\footnotetext{
${ }^{19}$ The number of countries decreased from 53 to 42 because I dropped seven countries that were among the 10 countries that I had dropped from the dataset of Klenow and Rodriguez-Clare, and because four countries in Caselli and Feyrer were not in Klenow and Rodriguez-Clare (Burundi, Cote d'Ivoire, Egypt, and Morocco).
} 


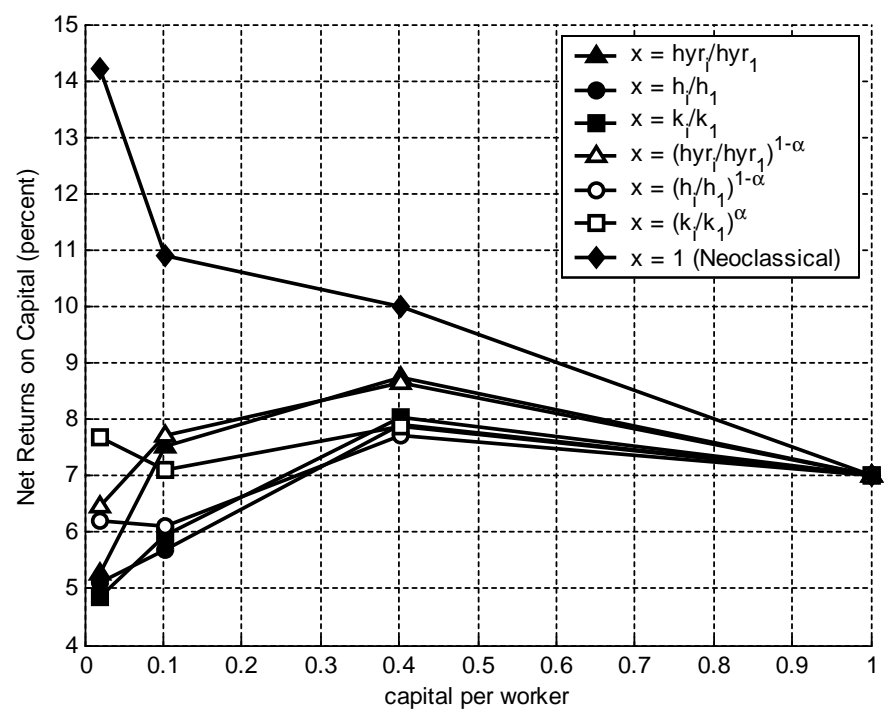

FIG. 2. Net returns to capital. Same procedure as in figure 1, with data from Klenow and Rodriguez-Clare (2005). Human capital calculated with the procedure to obtain BK4, as in Klenow and Rodriguez-Clare (1997), the same measure used in figure 1 and in Imrohoroglu and Kumar (2004). Physical capital for each quartile: $k_{i}=0.020$, $0.102,0.401,1$. Human capital for each quartile: $h_{i}=0.0354,0.143,0.523,1$. Physical and human capital normalized by the highest quartile.

predicts returns to capital between 6 and 10 percent, the predictions of the model agree with the data. ${ }^{20}$

I find returns to capital consistent with the estimates of Caselli and Feyrer but they explain the small difference in returns across countries in a different way. In Caselli and Feyrer, the difference in returns is small because poor countries have more land in the production function and agriculture is more important in GDP. Here, the difference in returns is small because high-ability managers in poor countries are more difficult to find. The two explanations are related. If in poor countries there

\footnotetext{
${ }^{20}$ I also calculated output per worker for the four quartiles using the proxies for managerial ability. According to the data in Klenow and Rodriguez-Clare (1997), output per worker from the first to the fourth quartile is $1.0,2.7,6.0,13.5$, normalized by the first quartile. The model predicts larger variation in output per worker. The proxy with higher education, for example, implies output per worker of 1.0, 3.9, 11.2, and 33.6 (the different proxies imply similar results, the average across proxies is $1.0,3.7,10.8$, and 32.9 ).
} 
are not institutions that allow agents to keep the output of their work, or if there are institutions that block entrepreneurial behavior, then agents will not invest in managerial ability. It will be harder to find high-ability managers and traditional sectors, such as agriculture, will be more important in these countries.

What is the direct evidence on managerial ability across countries? I have used so far physical capital, human capital and years of higher education to define proxies for managerial ability. The advantage is that data for $k, h$, and hyr exist for many countries and, as these variables have been used extensively in other applications, we know more precisely their properties. But it is useful to use direct measures of managerial ability, even if we have data for less countries.

I now use a direct measure of managerial ability. The data is from the Global Entrepreneurship Monitor (GEM). The GEM produces a database on entrepreneurship comparable across countries. Its first survey was in 1999, with 10 countries, and its most recent survey, in 2007, had 42 countries. The GEM asks the same questions to a sample of two thousand individuals in each country. It defines an entrepreneur as someone creating a firm or an owner and manager of a new firm (firms up to 3.5 years old). Reynolds et al. (2005) describe the implementation of GEM and discuss the survey questions and the reliability of the dataset. Ardagna and Lusardi (2008) discuss further the reliability of the GEM dataset.

I focus on the indices of total entrepreneurship activity out of necessity (teanec), and total entrepreneurship activity to pursue an opportunity (teaopp). The total entrepreneurship activity is the ratio of entrepreneurs to the number of individuals in the sample. The question "You are, alone or with others, currently trying to start a new business, including any self-employment or selling any goods or services to others?," as it is in Reynolds et al. (2005) (and other questions to assure that the initiative is recent and that the person took actions to start the business), identify an entrepreneur. All indices restrict to individuals aged 18 to 64 . An advantage of having 
interviews instead of governmental records is the inclusion of firms in the formal and informal sectors and of people creating a business without having it registered yet. "Are you involved in this start-up/firm to take advantage of a business opportunity or because you have no better choices of work?," identify the activity as for necessity or opportunity.

I relate managerial ability in the model to entrepreneurship for opportunity. Risky projects in the model are potentially more productive they have $A_{H}>A$-but represent new technologies with a risk of producing zero. Countries with more entrepreneurs for opportunity than for necessity have more managers that choose the risky project and so have more high ability managers.

The entrepreneurship indices for necessity and opportunity behave in different ways in poor and rich countries. Total entrepreneurship activity and the indices teanec and teaopp are larger in poor countries (probably because poor countries have a larger informal sector and more small firms), but entrepreneurship for opportunity is more frequent than entrepreneurship for necessity in rich countries: the ratio teaopp/teanec is higher in rich countries. Ardagna and Lusardi (2008) regress the entrepreneurship indices on education and other individual characteristics. They find that entrepreneurs for opportunity have more education and more confidence in their skills than entrepreneurs for necessity.

Let the proxy for managerial ability in a country be now defined as the ratio teaopp/teanec. I use the GEM surveys from 2001 to 2004 (the questionnaire is more comparable across years after 2001, the data for 2004 is the most recent available on public domain). I match the countries in the GEM dataset to the countries in the quartiles of Klenow and Rodriguez-Clare (1997), I obtain 35 countries. As in Caselli and Feyrer, the dataset is concentrated in the richer countries. From the 22 countries in each quartile of Klenow and Rodriguez-Clare, there are 21 countries in the richest quartile in the GEM dataset, and 11, 2 and 1 country in the third, second, and first 
quartiles. The two countries in the second quartile are Thailand and India. The single country in the first quartile is Uganda. Each country has at most four observations, one for each survey from 2001 to 2004. Taking each observation as a country in each year implies 108 observations, 75 for the richest quartile and 28, 3, and 2 observations for the other quartiles. I define proxies for each quartile with the 35 countries and with the 108 observations in countries and years of surveys. It makes difference, as there are little observations for the first and second quartile.

Let $g_{i}$ be the average of the ratio teaopp/teanec for each quartile. I define $x=g_{i} / g_{1}$, in the same way as for the proxies with $h, k$, and $h y r$, and recalibrate the model with the data from GEM. ${ }^{21}$ I obtain net returns to capital from the poorest to the richest quartile of $7.3,8.3,6.8$, and 7.0 percent, with the 35 countries, and 7.3, 7.4, 6.7, and 7.0 percent with the 108 observations. The main difference is the return in the second quartile, smaller with 108 observations. The reason is that Thailand is an outlier with teaopp/teanec equal to 5.5, with one survey in 2002, well above the teaopp/teanec of India, the other available country in the second quartile, equal to 1.9 and 0.8 with surveys in 2002 and 2001. Among the 35 countries, Thailand is the 15th in teaopp/teanec, just above U.K. (with 5.3) and Ireland (with 5.2). With 35 countries or 108 observations, the returns are consistent with the results in figure 1. The peak of returns is now in the second quartile, but the difference in returns across quartiles is small. Moreover, the number of countries in the third and second quartiles decreased from 22 to 11 countries in the third and 2 countries in the second quartile, which decreases the precision of the point estimates and increases the probability of having similar returns to capital, about seven percent for all countries. The returns

\footnotetext{
${ }^{21}$ With the 35 countries, the teaopp/teanec for a country is the average of the four surveys for each year, I then take the average of the countries in each quartile to obtain $g_{i}$. With the 108 observations in country and years of surveys, I take the average of the observations for each quartile. With the 35 countries, $g_{i}=1.15,3.40,2.59,7.78$ from the poorest to the richest quartile. With the 108 observations, $g_{i}=1.15,2.71,2.56,7.96$. $A$ and $A_{H}$ are similar for the two specifications, the values in the appendix are for the 108 observations.
} 
agree with the previous findings, but the results are sharper by avoiding the effect of outliers, as we see next.

To avoid the effect of outliers, I calculated $g_{i}$ with income per capita for each quartile and the coefficients of the regression of teaopp/teanec of each country on income per capita. ${ }^{22}$ I found returns to capital equal to $6.1,7.0,9.2$, and 7.0 percent. The peak of returns, in this case, is back to the third quartile. The pattern of returns is very similar to the pattern with the other proxies in figure 1. Using the GEM dataset does not change the conclusions obtained with the other proxies.

Additional evidence on managerial ability across countries comes from the increasing literature about the effect of managerial ability on firm value. Bloom and Van Reenen (2007) find a large spread in management practices across medium firms in U.S., U.K., France and Germany. One of the most important factors to explain the dispersion of managerial ability is the transmission of control. They find that familyowned firms in which the Chief Executive Officer is the eldest male child tend to have lower indicators of managerial ability. Caselli and Gennaioli (2005) state that it is more common to have the transmission of ownership and control from one generation to the other in poor countries. ${ }^{23}$ Combined with the evidence that firms managed by the descendants of the owner have lower managerial ability, they argue that we should expect lower managerial ability in poorer countries. Gabaix and Landier (2008), on the other hand, calibrate their model with a very low dispersion of managerial ability. They focus on managerial abilities of the top CEOs (the CEOs of the largest firms) to study executive compensation. The managers in the present model, however, are all managers in a country, not only the top CEOs, and we should expect a higher dispersion of managerial ability for the whole population of managers. The evidence in

\footnotetext{
${ }^{22}$ The values of $g_{i}$ with this procedure are $0.36,1.37,3.22,7.58$.

${ }^{23}$ See the references in Bloom and Van Reenen and Caselli and Gennaioli for the forms of transmission of ownership and control across countries, and for additional evidence on the impact of family control on firm value and managerial ability.
} 
these papers agrees with the indicators in the GEM dataset. I use the GEM dataset in the simulations because it has more comparable data across countries and more countries.

Before using the GEM dataset, I defined proxies for $x$ based on human capital, physical capital and years of higher education. Is education a good proxy for managerial ability? I discuss this question in more detail now. I add evidence from Ardagna and Lusardi (2008), Wadhwa et al. (2008), and Cascio et al. (2008). Ardagna and Lusardi, as mentioned above, find that entrepreneurs for opportunity have more education. In more detail, the variables for high school and college are positively related to entrepreneurship for opportunity and negatively related to entrepreneurship for necessity. These results are controlled for income (income is positively related to entrepreneurship for opportunity). Wadhwa et al., in a study on the founders of firms of computers, bioscience, software and other related areas, find that 92 percent of the founders have at least college and 47 percent have master's or doctoral degrees. They find that college graduates founded firms with two times the revenues and the number of employees of firms founded by those with high school only, another evidence on the relation of education and managerial ability. Cascio et al. find that higher education is more important than total years of education to increase proficiency on arithmetic, reading and the ability to use information, skills usually related to managerial ability. This finding agrees with the sharp predictions in figure 1 when using higher education as proxy.

I end this section by discussing the link between managerial ability and institutions. What moves the distribution of managerial ability? Institutions or other factors such as human capital or physical capital? Put simply, forcing people to study will not increase the number of high-ability managers. ${ }^{24}$ Managerial ability is defined as the

\footnotetext{
${ }^{24}$ Or, as Easterly (2001, p. 73) writes: "Having the government force you to go to school does not change your incentives to invest in the future."
} 
probability of being successful in risky projects. Learning to increase the probability of being successful in risk projects requires taking conscious actions toward this purpose.

Institutions affect actions. Murphy et al. (1991) present a model in which agents use their talents in productive activities, such as innovation, or in activities that do not produce but only redistribute wealth, such as rent seeking. If agents believe that they cannot keep the profits from their activities - if institutions cannot guarantee these rights - then they will use their talents in rent seeking rather than in innovation. Pritchett $(2001,2006)$ finds little evidence that growth in education implies economic growth. As he points out, one explanation is that, in accordance with the model of Murphy et al., education may be biased for unproductive activities. Education increases growth only if educated people work in productive activities.

In the same way, agents use education to increase managerial ability if the institutions in place encourage entrepreneurship. Dias and McDermott (2006) present a model that emphasizes this mechanism. In their model, better institutions increase the supply of entrepreneurs. Moreover, education raises the number of entrepreneurs, but it is not as effective as better institutions. Dias and McDermott also find evidence that economies with more entrepreneurs have more demand for education.

Therefore, what moves the distribution of ability is, ultimately, institutions. In the simulations, I use human capital, physical capital, higher education, and entrepreneurship for $x$ instead of using institutions. The variables that I used, however, are positively related to institutions. Good institutions in place for a long time imply high levels of human capital, physical capital, higher education, and entrepreneurship.

Desai et al. (2003) and Ardagna and Lusardi (2008) find evidence that institutions affect entrepreneurship. Desai et al., in a sample of European countries, find that less corruption and more protection of property rights increase rates of entry, decrease rates of exit, and lower average firm size. Ardagna and Lusardi, with the GEM dataset, find that more efficient judicial systems and less stringent entry and labor 
market regulations increase entrepreneurship for opportunity. If agents believe that they can start a new business to pursue an opportunity, they will investment in managerial ability. The model presented here takes managerial ability as given to show that more managerial ability implies higher returns to capital. But the decision to invest in managerial ability is a result of institutions. An extension of the model is to include the decision to invest in managerial ability. Agents will invest in managerial ability if they have incentives to do so.

\section{CONCLUSION}

This paper shows how managerial ability can increase total factor productivity and explain capital flows. Managerial ability increases the number of risky projects. All countries have access to the same technology and the technology has decreasing returns to capital. Nevertheless, returns in poor countries are smaller than returns in rich countries. The availability of high-ability managers compensates the decreasing productivity of capital.

I construct proxies for managerial ability with physical capital, human capital, years of higher education, and indicators of entrepreneurship. Returns are close across countries, the model predicts, and middle-income countries have higher returns to capital than poor and rich countries.

The model also explains why capital flows have maintained their pattern although financial innovation decreased intermediation costs. As it is more difficult to increase managerial ability, richer countries can have higher returns to capital if their distribution of managerial abilities is more favorable.

One way to understand the results is that there are no frictions for capital movements but there are relevant frictions for the movement of managerial ability. One extension of the model is to allow capital flows to combine flows of capital and managerial ability. In this way, we can look for predictions on the flows of managerial 
ability across countries. Another important direction for research is to understand why agents would not invest in their managerial abilities in poor countries. Institutions are probably important for investment in managerial abilities. There will be entrepreneurs only if there are institutions that enable them to exist.

\section{REFERENCES}

Ardagna, Silvia, and Annamaria Lusardi (2008). "Explaining International Differences in Entrepreneurship: The Role of Individual Characteristics and Regulatory Constraints." NBER Working Paper 14012.

Barro, Robert J., and Jong Wha Lee (2001). "International Data on Educational Attainment: Updates and Implications." Oxford Economic Papers, 53(3): 541-563.

Bates, Timothy (1990). "Entrepreneur Human Capital Inputs and Small Business Longevity." Review of Economics and Statistics, 72(4): 551-559.

Bils, Mark, and Peter J. Klenow (2000). "Does Schooling Cause Growth?" American Economic Review, 90(5): 1160-1183.

Bloom, Nick, and John Van Reenen (2007). "Measuring and Explaining Management Practices Across Firms and Countries." Quarterly Journal of Economics, 122(4): 1351-1408.

Caselli, Francesco (2005). "Accounting for Cross-Country Income Differences." In Philippe Aghion and Steven N. Durlauf (eds.), Handbook of Economic Growth, vol. 1A. North-Holland: Amsterdam.

Caselli, Francesco, and James Feyrer (2007). "The Marginal Product of Capital." Quarterly Journal of Economics, 122(2): 535-568.

Caselli, Francesco, and Nicola Gennaioli (2005). "Dynastic Management." Working Paper.

Cascio, Elizabeth, Damon Clark, and Nora Gordon (2008). "Education and the Age Profile of Literacy into Adulthood." Journal of Economic Perspectives, $22(3): 47-70$.

Desai, Mihir, Paul Gompers, and Josh Lerner (2003). "Institutions, Capital Constraints and Entrepreneurial Firm Dynamics: Evidence from Europe." NBER Working Paper 10165. 
Dias, Joilson, and John McDermott (2006). "Institutions, Education, and Development: The Role of Entrepreneurs." Journal of Development Economics, 80(2): 299-328.

Easterly, William (2001). The Elusive Quest for Growth. MIT Press: Cambridge, Massachusetts.

Foster, Andrew D., and Mark R. Rosenzweig (1996). "Technical Change and Human-Capital Returns and Investments: Evidence from the Green Revolution." American Economic Review, 86(4): 931-953.

Foster, Andrew D., and Mark R. Rosenzweig (2004). "Technological Change and the Distribution of Schooling: Evidence from Green-Revolution India." Journal of Development Economics, 74(1): 87-111.

Gabaix, Xavier, and Augustin Landier (2008). "Why Has CEO Pay Increased So Much?" Quarterly Journal of Economics, 123(1): 49-100.

Gourinchas, Pierre-Olivier, and Olivier Jeanne (2007). "Capital Flows to Developing Countries: the Allocation Puzzle." NBER Working Paper 13602.

Hall, Robert E., and Charles I. Jones (1999). "Why Do Some Countries Produce So Much More Output per Worker than Others?" Quarterly Journal of Economics, 114(1): 83-116.

Hanushek, Eric A., and Ludger Woessmann (2007). "The Role of School Improvement in Economic Development." NBER Working Paper 12832.

Imrohoroglu, Ayse, and Krishna B. Kumar (2004). "Intermediation Costs and Capital Flows." Review of Economic Dynamics, 7(3): 586-612.

Klenow, Peter J., and Andrés Rodriguez-Clare (1997). "The Neoclassical Revival in Growth Economics: Has It Gone Too Far?" In Ben S. Bernanke and Julio J. Rotemberg (eds.), NBER Macroeconomics Annual 1997: 73-103. MIT Press, Cambridge, Massachusetts.

Klenow, Peter J., and Andrés Rodriguez-Clare (2005). "Externalities and Growth." In Philippe Aghion and Steven N. Durlauf (eds.), Handbook of Economic Growth, vol. 1A. North-Holland: Amsterdam.

Kumar, Krishna B. (2003). "Education and Technology Adoption in a Small Open Economy: Theory and Evidence." Macroeconomic Dynamics, 7(4): 586-617.

Lazear, Edward P. (2005). "Entrepreneurship." Journal of Labor Economics, 23(4): 649-680. 
Lucas, Robert E., Jr. (1978). "On the Size Distribution of Business Firms." Bell Journal of Economics, 9(2): 508-523.

Lucas, Robert E., Jr. (1990). "Why Doesn't Capital Flow from Rich to Poor Countries?" American Economic Review, 80(2): 92-96.

Murphy, Kevin M., Andrei Shleifer, and Robert W. Vishny (1991). "The Allocation of Talent: Implications for Growth." Quarterly Journal of Economics, 106(2): 503-530.

Prescott, Edward C. (1998). "Needed: a Theory of Total Factor Productivity." International Economic Review, 39(3): 525-551.

Pritchett, Lant (2001). "Where Has All the Education Gone?" The World Bank Economic Review, 15(3): 367-391.

Pritchett, Lant (2006). "Does Learning to Add Up Add Up? The Returns to Schooling in Aggregate Data." In Erik Hanushek and F. Welch (eds), Handbook of the Economics of Education, vol. 1. North-Holland: Amsterdam.

Rauch, James E. (1991). "Reconciling the Pattern of Trade with the Pattern of Migration." American Economic Review, 81(4): 775-796.

Reinhart, Carmen M., and Kenneth S. Rogoff (2004). "Serial Default and the 'Paradox' of Rich-to-Poor Capital Flows." American Economic Review, 94(2): $53-58$.

Reynolds, Paul, Niels Bosma, Erkko Autio, Steve Hunt, Natalie De Bono, Isabel Servais, Paloma Lopez-Garcia, and Nancy Chin (2005). "Global Entrepreneurship Monitor: Data Collection Design and Implementation 19982003." Small Business Economics, 24: 205-231.

UNCTAD (2006). World Investment Report 2006. United Nations: New York and Geneva.

Vandenbussche, Jerome, Philippe Aghion, and Costas Meghir (2006). "Growth, Distance to Frontier and Composition of Human Capital." Journal of Economic Growth, 11(2): 97-127.

Wadhwa, Vivek, Richard Freeman, Ben Rissing (2008). "Education and Tech Entrepreneurship." Working Paper, Ewing Marion Kauffman Foundation. 


\section{APPENDIX}

Proposition 1. $\zeta(z, x)$ is increasing in $x$. Proof. As $\pi$ is positive and increasing, by the mean value theorem for integrals, there exists a $c, z \leq c \leq 1$, such that $\Phi(z, x)=\int_{z}^{1} \pi(a) f(a, x) d a=\pi(c, x) \int_{z}^{1} f(a, x) d a$, where $x$ is written in $\pi(c, x)$ to emphasize the dependency of $c$ on the distribution function. Then,

$$
\zeta(z, x) \equiv \frac{\Phi(z, x)}{1-F(z, x)}=\frac{\pi(c, x) \int_{z}^{1} f(a, x) d a}{\int_{z}^{1} f(a, x) d a}=\pi(c, x) .
$$

So, we have to prove that $c$ increases when $x$ increases. Define $c_{1}$ as the value of $c$ such that $\pi\left(c_{1}\right) \int_{z}^{1} f\left(a, x_{1}\right) d a=\int_{z}^{1} \pi(a) f\left(a, x_{1}\right) d a$, and analogously for $c_{2}$. We have, for $x_{2}>x_{1}$,

$$
\Delta_{\Phi} \equiv \Phi\left(z, x_{2}\right)-\Phi\left(z, x_{1}\right)=\pi\left(c_{2}\right) \int_{z}^{1} f\left(a, x_{2}\right) d a-\pi\left(c_{1}\right) \int_{z}^{1} f\left(a, x_{1}\right) d a>0
$$

where the expression is greater than zero by first order stochastic dominance.

Rewrite $\Delta_{\Phi}$ as

$$
\Delta_{\Phi}=\pi\left(c_{1}\right)\left[\frac{\pi\left(c_{2}\right)}{\pi\left(c_{1}\right)} \int_{z}^{1} f\left(a, x_{2}\right) d a-\int_{z}^{1} f\left(a, x_{1}\right) d a\right] .
$$

We have that $\pi\left(c_{2}\right)=\pi\left(c_{1}\right)+\Delta_{\pi}$ for some $\Delta_{\pi}$. We have to prove that $\Delta_{\pi}>0$. This implies that $\pi\left(c_{2}\right)>\pi\left(c_{1}\right)$ and so $c_{2}>c_{1}$ as $\pi$ is increasing. Using $\pi\left(c_{2}\right)=\pi\left(c_{1}\right)+\Delta_{\pi}$ in the equation above yields

$$
\begin{gathered}
\Delta_{\Phi}=\pi\left(c_{1}\right)\left[\int_{z}^{1} f\left(a, x_{2}\right) d a-\int_{z}^{1} f\left(a, x_{1}\right) d a+\frac{\Delta_{\pi}}{\pi\left(c_{1}\right)} \int_{z}^{1} f\left(a, x_{2}\right) d a\right] \\
\Rightarrow \Delta_{\Phi}=\pi\left(c_{1}\right) \int_{z}^{1}\left[f\left(a, x_{2}\right) d a-f\left(a, x_{1}\right)\right] d a+\Delta_{\pi} \int_{z}^{1} f\left(a, x_{2}\right) d a
\end{gathered}
$$

Also,

$$
\begin{gathered}
\Delta_{\Phi} \equiv \Phi\left(z, x_{2}\right)-\Phi\left(z, x_{1}\right)=\int_{z}^{1} \pi(a) f\left(a, x_{2}\right) d a-\int_{z}^{1} \pi(a) f\left(a, x_{1}\right) d a \\
\Rightarrow \Delta_{\Phi}=\int_{z}^{1} \pi(a)\left[f\left(a, x_{2}\right)-f\left(a, x_{1}\right)\right] d a .
\end{gathered}
$$


Equating (15) and (16) implies

$$
\begin{gathered}
\int_{z}^{1} \pi(a)\left[f\left(a, x_{2}\right)-f\left(a, x_{1}\right)\right] d a=\pi\left(c_{1}\right) \int_{z}^{1}\left[f\left(a, x_{2}\right) d a-f\left(a, x_{1}\right)\right] d a \\
+\Delta_{\pi} \int_{z}^{1} f\left(a, x_{2}\right) d a \\
\Rightarrow \int_{z}^{1}\left[\pi(a)-\pi\left(c_{1}\right)\right] f\left(a, x_{2}\right) d a=\int_{z}^{1}\left[\pi(a)-\pi\left(c_{1}\right)\right] f\left(a, x_{1}\right) d a+\Delta_{\pi} \int_{z}^{1} f\left(a, x_{2}\right) d a \\
\Rightarrow \int_{z}^{1}\left[\pi(a)-\pi\left(c_{1}\right)\right] f\left(a, x_{2}\right) d a=\Delta_{\pi} \int_{z}^{1} f\left(a, x_{2}\right) d a,
\end{gathered}
$$

as $\int_{z}^{1}\left[\pi(a)-\pi\left(c_{1}\right)\right] f\left(a, x_{1}\right) d a=0$ by the definition of $c_{1}$.

Looking for a contradiction, suppose that $\Delta_{\pi}=\pi\left(c_{2}\right)-\pi\left(c_{1}\right) \leq 0$. Then

$$
\int_{z}^{1}\left[\pi(a)-\pi\left(c_{1}\right)\right] f\left(a, x_{2}\right) d a \leq 0
$$

However, as $F\left(a, x_{2}\right)$ first order stochastically dominates $F\left(a, x_{1}\right)$,

$$
\int_{0}^{1}\left[\pi(a)-\pi\left(c_{1}\right)\right] f\left(a, x_{2}\right) d a>\int_{0}^{1}\left[\pi(a)-\pi\left(c_{1}\right)\right] f\left(a, x_{1}\right) d a=0
$$

as $\pi(a)-\pi\left(c_{1}\right)$ is increasing in $[0,1]$. Therefore,

$$
\int_{0}^{z}\left[\pi(a)-\pi\left(c_{1}\right)\right] f\left(a, x_{2}\right) d a+\int_{z}^{1}\left[\pi(a)-\pi\left(c_{1}\right)\right] f\left(a, x_{2}\right) d a>0 .
$$

For the strict inequality, we have to assume that $f$ is positive in $[0, z]$. According to (18), in order to have (19) we must have

$$
\int_{0}^{z}\left[\pi(a)-\pi\left(c_{1}\right)\right] f\left(a, x_{2}\right) d a>0 .
$$

This implies

$$
\int_{0}^{z} \pi(a) f\left(a, x_{2}\right) d a>\pi\left(c_{1}\right) \int_{0}^{z} f\left(a, x_{2}\right) d a .
$$

But, we know that $\pi(z) \int_{0}^{z} f\left(a, x_{2}\right) d a>\int_{0}^{z} \pi(a) f\left(a, x_{2}\right) d a$ and so

$$
\pi(z) \int_{0}^{z} f\left(a, x_{2}\right) d a>\pi\left(c_{1}\right) \int_{0}^{z} f\left(a, x_{2}\right) d a \Rightarrow \pi(z)>\pi\left(c_{1}\right) .
$$


However, according to the definition of $c_{1}$,

$$
\pi\left(c_{1}\right) \int_{z}^{1} f\left(a, x_{1}\right) d a=\int_{z}^{1} \pi(a) f\left(a, x_{1}\right) d a \Rightarrow \pi\left(c_{1}\right) \geq \pi(z),
$$

which is a contradiction. Therefore, we have to accept that

$$
\Delta_{\pi}>0 \Rightarrow \pi\left(c_{2}\right)>\pi\left(c_{1}\right) \Rightarrow \zeta\left(z, x_{2}\right)>\zeta\left(z, x_{1}\right) \text {. }
$$

Corollary. The ratio of capital in risky projects to capital in safe projects is increasing in $x$.

Proof. Define $\theta(z, x) \equiv k_{r} / k_{s}=\left[\zeta(z, x) \frac{A_{H}}{A}+[1-\zeta(z, x)] \frac{A_{L}}{A}\right]^{\frac{1}{1-\alpha}}$. Therefore, $\theta_{x}(z, x)>0$ if and only if $\zeta_{x}\left(A_{H} / A-A_{L} / A\right)>0$, which is true as $\zeta_{x}>0$ and $A_{H}>A_{L}$.

\section{Results for propositions 2,3 and 4}

1. $\zeta(z, x)>\pi(z)$ if $\pi$ is increasing. Used in propositions 2,3 and 4 .

$\zeta(z, x) \equiv \int_{z}^{1} \pi(a) f(a, x) d a / \int_{z}^{1} f(a, x) d a$. As $\pi$ is positive and increasing, there exists a $c, z<c<1$, such that $\zeta(z, x)=\pi(c) \int_{z}^{1} f(a, x) d a / \int_{z}^{1} f(a, x) d a=\pi(c)>$ $\pi(z)$. If $\pi(z) \geq z$ we also have $\zeta>z$. As $\zeta$ is increasing in $x$, then $\zeta(z, x>1)>$ $\zeta(z, 1)>\pi(z)$.

2. $\theta \equiv k_{r} / k_{s}>1$ if $A_{L}$ is sufficiently small. Used in proposition 4.

This property says that the quantity of capital in risky projects is higher than the quantity used in safe projects. By the equilibrium condition $\Lambda=1$, we have, if $A_{L}=0, \frac{1}{1-\alpha} \theta^{\alpha}(\pi(z)-\alpha \zeta) \frac{A_{H}}{A}=1, \theta \equiv k_{r} / k_{s}$. By (8), $A_{H} / A=\theta^{1-\alpha} \zeta^{-1}$. Therefore, $\theta=\frac{1-\alpha}{\pi(z) / \zeta-\alpha}>1$ as $\zeta>\pi$ and $\pi / \zeta-\alpha>0$ by the equilibrium condition. By continuity, this condition is also true if $A_{L}$ is sufficiently close to zero.

Proposition 2. Existence of $z, 0<z<1$. Proof. Define $\Lambda(z, x)$ as the left-hand side of (9). $\Lambda$ is the ratio of the expected profits from the risky project with ability $z$ to the profit from the safe project. The strategy of the proof is to show that we have $\Lambda(1, x)>1$, if $\pi(1)$ is sufficiently high, and $\Lambda(0, x)<0$, if $A_{L} / A_{H}$ and $\pi(0)$ are sufficiently small. As $\Lambda(z, x)$ is continuous, there exists a $z, 0<z<1$. These conditions are met, for example, with $\pi(a)=a$ and $A_{L}=0$.

For $\Lambda(1, x)>1$. We have $\lim _{z \rightarrow 1} \zeta(z, x)=-\Phi^{\prime}(z) / F^{\prime}(z)=\pi(1)>0$. Then $\lim _{z \rightarrow 1} \Lambda(z, x)=\lim _{z \rightarrow 1}\left(\pi \frac{A_{H}}{A}+(1-\pi) \frac{A_{L}}{A}\right)^{\frac{1}{1-\alpha}}>1$ if $\pi(1)$ is sufficiently close to one.

For $\Lambda(0, x)<0$. We have $\zeta(0, x)=\int_{0}^{1} \pi(a) f(a, x) d a>0$. Then, as $k_{r} / k_{s}>0$, 
$\Lambda(0, x)<0$ if and only if $[\pi(0)-\alpha \zeta(0, x)] \frac{A_{H}}{A_{L}}+[(1-\pi(0))-\alpha(1-\zeta(0, x))]<0$. The second term in the left-hand side is positive as $\zeta(z, x)>\pi(z)$. Therefore, $\Lambda(0, x)<0$ if and only if $\frac{A_{L}}{A_{H}}<\frac{\alpha \zeta(0, x)-\pi(0)}{1-\pi(0)-\alpha(1-\zeta(0, x))}$. This condition is satisfied if $A_{L} / A_{H}$ and $\pi(0)$ are sufficiently close to zero.

Proposition 3. $z$ is increasing in $x$. Proof. Consider that $0<z<1$. Therefore, $z$ is given by $\Lambda(z, x)=1$, where $\Lambda$ is the left-hand side of $(9)$, and $z_{x}=-\Lambda_{x} / \Lambda_{z}$. $\Lambda_{x}<0$ in general and $\Lambda_{z}>0$ for certain conditions given below. Hence $z_{x}>0$.

a. $\Lambda_{x}<0$

Write $\Lambda(z, x)=\frac{1}{1-\alpha}\left[\theta^{\alpha} E_{\pi}[\tilde{A} / A]-\alpha \theta\right]$, where $\theta \equiv k_{r} / k_{s}$ and $E_{\pi}[\tilde{A} / A]=$ $\pi(z) \frac{A_{H}}{A}+[1-\pi(z)] \frac{A_{L}}{A}$. Therefore, $\Lambda_{x}(z, x)=\frac{\alpha \theta_{x}}{1-\alpha} \frac{1}{\theta^{1-\alpha}}\left[E_{\pi}[\tilde{A} / A]-\theta^{1-\alpha}\right]$. So, $\Lambda_{x}(z, x)<0$ if and only if $E_{\pi}[\tilde{A} / A]-\theta^{1-\alpha}<0$, as $\theta_{x}>0$. We have $E_{\pi}[\tilde{A} / A]-$ $\theta^{1-\alpha}=-(\zeta-\pi(z))\left(A_{H} / A-A_{L} / A\right)<0$, as $\zeta>\pi(z)$. Therefore, $\Lambda_{x}(z, h)<0$.

b. $\Lambda_{z}>0$

Recall that the first order conditions imply $\Lambda(z, x)=1$. We have $\Lambda(0, x)<0$ and $\Lambda(1, x)>1$. If $z$ is unique, then $\Lambda$ in increasing in its first argument in the neighborhood of $z$ and so $\Lambda_{z}>0$. In all functional forms considered in this paper, $z$ is unique. But there can be particular forms of $f(a, x)$ such that $z$ is not unique. In this case, the maximum of the objective function must be for the smallest $z$ such that $\Lambda(z, x)=1$ because, with this, there are more managers that undertake the risky project (I present a formal argument below). As $\Lambda(0, x)<0$, the smallest $z$ for which $\Lambda(z, x)=1$ is such that $\Lambda$ is increasing in $z$ in its neighborhood and so $\Lambda_{z}>0$.

The formal argument that follows presents a condition to imply $\Lambda_{z}>0$. We have $\Lambda(z, x)=\frac{1}{1-\alpha} \theta^{\alpha}\left[(z-\alpha \zeta) \frac{A_{H}}{A}+[(1-z)-\alpha(1-\zeta)] \frac{A_{L}}{A}\right]$. For the optimal $z$, as $\Lambda=1$, this implies $\Lambda_{z}=\alpha \frac{\theta_{z}}{\theta}+\frac{1}{1-\alpha} \theta^{\alpha}\left(\frac{A_{H}}{A}-\frac{A_{L}}{A}\right)\left(1-\alpha \zeta_{z}\right)$. With $\theta_{z}=\frac{1}{1-\alpha} \theta^{\alpha} \zeta_{z}\left(\frac{A_{H}}{A}-\frac{A_{L}}{A}\right)$ we have $\Lambda_{z}=\frac{1}{1-\alpha} \theta^{\alpha-1}\left(\frac{A_{H}}{A}-\frac{A_{L}}{A}\right)\left[\left(1-\alpha \zeta_{z}\right) \theta+\alpha \zeta_{z}\right]$. Therefore, $\Lambda_{z}>0$ if and only if $\zeta_{z}<\frac{1}{\alpha} \frac{\theta}{\theta-1}\left(\theta>1\right.$, see above). We have $\frac{1}{\alpha} \frac{\theta}{\theta-1}>1$ and usually $\zeta_{z}<1$ (in particular, $\lim _{z \rightarrow 1} \zeta_{z}=1 / 2$ ). But it can be the case that $\zeta_{z}>1$ for certain values of $z$ and $x$. Use the definition of $\zeta$ to write $\zeta_{z}=\frac{f(z)}{\int_{z}^{1} f(a) d a}(\zeta-\pi)$. Then, use the optimality condition $\Lambda=1$ to obtain $\zeta-\pi=\frac{1-\alpha}{\alpha}\left(\pi(z)-\theta^{-\alpha} A / A_{H}\right)$, for $A_{L}=0$ (the argument is the same for $A_{L} \neq 0$ ). Hence, $\zeta_{z}<\frac{1}{\alpha} \frac{1}{1-1 / \theta}$ if and only 
if $\pi(z)<\frac{1}{1-1 / \theta} \frac{1}{1-\alpha} \frac{1-F(z)}{f(z)}+\theta^{-\alpha}\left(\frac{A_{H}}{A}\right)^{-1}$. We have $\frac{1}{1-1 / \theta}>1, \frac{1}{1-\alpha}>1$ and $\theta^{-\alpha}\left(\frac{A_{H}}{A}\right)^{-1}>0$. If we have multiple $z$ 's, the smallest one will be such that $1-F(z)$ is large. So, this condition is probably always met although $[1-F(z)] / f(z)$ may be smaller than 1 . Another way of having the inequality above is assuming that the distribution of abilities is not concentrated in any level of ability and so $f(z)$ is small. A sufficient condition is simply $\zeta_{z}<1 / \alpha$.

Proposition 4. TFP is increasing in $x$. Proof. TFP is equal to $A \Gamma(x)^{1-\alpha}$. So, we have to prove that $\Gamma(x)$ is increasing in $x$. As $\Gamma(x)=k / k_{s}(x)$, this property says that the quantity of capital invested in the safe project decreases with $x$, as stated in the text. As $\Gamma(z, x)=F(z, x)+[1-F(z, x)] \theta$, we have two effects of the increase in $x$. The first effect is the direct increase in $\theta$, as $\theta_{x}>0$, and the decrease in $F$, as $F_{x}<0$. The decrease in $F$ has a net positive effect because $F_{x}-F_{x} \theta=-F_{x}(\theta-1)>0$, as $\theta>1$. Therefore, the first effect is positive. The second effect is caused by the increase in $z$ implied by $z_{x}>0$. Formally, $\Gamma_{x}>0$ if and only if $[1-F(z, x)]\left(\theta_{z} z_{x}+\theta_{x}\right)-(\theta-1) F_{x}>f(z, x) z_{x}$. If $z_{x}>0$ is small, or if $f(z, x)$ is small ( $f$ is not concentrated in any particular ability) then this condition is verified as the left-hand side is always positive. We have $\lim _{x \rightarrow \infty} \Gamma(x)=\lim _{x \rightarrow \infty} \theta=$ $\left(A_{H} / A\right)^{\frac{1}{1-\alpha}}$.

Table A.1. Calibrated values of $A_{H}$ and $A$

\begin{tabular}{|c|c|c|c|}
\hline$x$ & $A_{H}$ & $A$ & $A_{H} / A$ \\
\hline$\left(h y r_{i} / h y r_{1}\right)^{1-\alpha}$ & 0.3860 & 0.2360 & 1.64 \\
\hline$\left(h_{i} / h_{1}\right)^{1-\alpha}$ & 0.3788 & 0.2356 & 1.61 \\
\hline$\left(k_{i} / k_{1}\right)^{\alpha}$ & 0.4148 & 0.2377 & 1.74 \\
\hline$h y r_{i} / h y r_{1}$ & 0.3543 & 0.2349 & 1.51 \\
\hline$h_{i} / h_{1}$ & 0.3497 & 0.2348 & 1.49 \\
\hline$k_{i} / k_{1}$ & 0.3417 & 0.2348 & 1.46 \\
\hline$g_{i} / g_{1}$ & 0.3799 & 0.2357 & 1.61 \\
\hline$x=1$ (Neoclassic) & 0.5459 & 0.2462 & 2.22 \\
\hline
\end{tabular}

The values of $A_{H}$ and $A$ were calibrated so that gross returns are equal to 16 percent per year and $k / y=3$ in the highest quartile. $A_{L}=0$ in all specifications. 